International Journal of Linguistics, Literature and Translation

ISSN: 2617-0299 (Online); ISSN: 2708-0099 (Print)

DOI: 10.32996/ijltt

Journal Homepage: www.al-kindipublisher.com/index.php/ijllt

\title{
The Journey of Young Professionals in The Translation Market: A Study Exploring Opportunities for Translators in Tripoli
}

\author{
Lujain Walid Mabruk ${ }^{1}$ (D) $ه$, Noorislam Abdulrahman Ghiblawi ${ }^{2}$ (D) and Aisha Abdulaziz Kabar ${ }^{3}$ (D) \\ ${ }^{123}$ Bachelor in Translation Studies, Translation Department, University of Tripoli, Tripoli, Libya \\ \Corresponding Author: Lujain Walid Mabruk, E-mail: lujainmabruk99@gmail.com
}

\author{
ARTICLE INFORMATION \\ Received: August 08, 2021 \\ Accepted: September 14, 2021 \\ Volume: 4 \\ Issue: 9 \\ DOI: $10.32996 /$ ijllt.2021.4.9.1
}

\section{KEYWORDS}

Translation job market, Job opportunities, Employers, Academic training, Training programs

\section{ABSTRACT}

This study explores the current state of the translation job market from the perspective of recent translation graduates. It attempts to evaluate the efficiency of the academic and technical training programs of the Department of Translation (DoT) at the University of Tripoli. The study examines how well DoT prepared graduates for professional work. It collects insights and analyzes a database of a variety of status indicators such as employment conditions, career options available for new translation graduates, domains that translators regularly search for: salary and income, occupational standards including years of experience and skills and qualifications required by employers. Based on evidence collected from the database, there is a wide range of employment positions and domains in which a translation graduate can occupy. However, quantitative analysis of the survey administered to translation graduates indicates that most graduates tend to work as teachers and could not obtain jobs as translators due to a shortage of opportunities and low salary intake in the translation industry. The study reveals that experience is not specified, and applicants with limited experience are also valued by employers in the 21st century job market. Nevertheless, the results of the investigation also suggest that IT skills, advanced language knowledge, and strong interpersonal skills are all crucial elements for job-seekers with no significant amount of experience. Furthermore, most graduates have a medium to negative perception of the university training and did not feel prepared enough to join the labor market after graduation. Although the vast majority of participants claim that the current situation in Tripoli had a direct impact on their job-seeking experience, about a third of the total participants surveyed revealed that they managed to obtain opportunities abroad using their translation degree.

\section{Introduction}

In recent years, there has been a growing interest in the study of professional translation education due to the increasing demand for translators worldwide. Many reports predict that careers in the translation industry will continue to grow over the following decades. A recent study shows that U.S. News and World Report ranked interpreters and translators as number one on their Best Creative \& Media Jobs list of 2020. The growing pervasiveness of translation has led to the development of translation into a full-grown independent discipline at bachelor, master, and doctoral levels in an array of universities and colleges. The University of Tripoli has recently created the Department of Translation with the aim of training professional translators in the two languages Arabic and English. Advanced knowledge of a foreign language continues to be a huge selling point when it comes to finding a job in an increasingly global market. Recent translation graduates, however, are often unsure which career path to take.

\section{K C AL-KINDI CENTER R D FOR RESEARCH AND DEVELOPMENT} Your gateway to world-class research

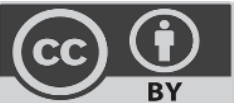

Published by Al-Kindi Center for Research and Development, London, United Kingdom. Copyright (c) the author(s). This open access article is distributed under a Creative Commons Attribution (CC-BY) 4.0 license 
The translation studies literature includes several studies that attempt to shed light on the state of the translation profession and the status of translators around the world. Bowker (2004) states that "these days translation is big business. This poses a great challenge for both employers who are seeking candidates with very specific skills and translator trainers who are faced with the task of turning out graduates who meet these demands". In his study titled What Does it Take to Work in the Translation Profession in Canada in the 21st Century? Exploring a Database of Job Advertisements, Bowker (2004) evaluates the current state of the Translation profession in Canada and determines what employers are looking for. The study analyzes a database of 301 job advertisements of translation-related positions collected over a three-year period from January 2000 to December 2002. He reports that the changing global marketplace is in need of translators and requires them to develop themselves to meet the market's expectations in terms of improving their computer skills, domain knowledge, fluent oral communication, specialized translation skills, and more.

Gümüş (2018) describes the state of the translation (not interpreting) profession in Turkey. Data was gathered from graduates of university translation programs representing freelancers, in-house translators, and language teachers. The results obtained in this study indicate an overwhelmingly high proportion of female translators, it shows that graduates consider working as freelance translators as a transitory option while they look for a 'better' job opportunity, and that freelancing is mostly not their primary role, and that most graduates are confident of their training. However, they do not trust themselves enough or feel prepared to enter the market after graduation.

Kafi et al. (2018) attempt to determine the challenges to establishing a professional status for translators in Iran, as well as offering solutions for improving the status. The study used an in-depth interview technique to collect qualitative data from a purposive sample of participants. In the interviews, the participants were asked to express their opinions about certain aspects concerning the status of the translation occupation in Iran and their recommendations for developing a prospective translation profession. The majority of interviewees in this study consider the lack of a representative translation guild as the main challenge for the development of the translation profession in Iran. The results of this study are in line with the findings of Katan (2009) who argues that anyone can claim the title of a translator in many countries around the world. Another major issue that affects the growth of the translation profession in Iran is the lack of an agreed-upon principle that all Iranian translators must follow. The findings of this study concluded that administrative challenges, issues of social status, academic and educational issues, issues related to translators and other translation agents, and economic challenges are all considered issues that represent the main obstacles to the development of a translation career in Iran. Based on the findings of this study, the first step towards professionalization seems to be the establishment of a representative translation guild. Moreover, the lack of experience of some translators and the need for further professional development in the form of translation workshops were among the major issues mentioned by the interviewees.

This study aims to determine the current challenges to establishing a professional status for translation graduates who graduated explicitly from the Translation Department at the University of Tripoli. This paper intends to explore the career options offered for newly graduated translation students. The research also highlights different recommended qualifications and skills that could increase translation graduates' chances of getting their foot into the job market.

\subsection{Research questions}

1. In Tripoli, what are the domains in which translators can be hired?

2. What are the job opportunities available for Translation graduates in Tripoli?

3. What are the skills and tools new translators need to equip to land satisfactory jobs as fast as possible?

4. What other career prospects can a Translation graduate follow in a world where unemployment is on the rise?

5. What is the average salary for a newly qualified translator?

\subsection{Objectives of the study}

Opportunities for job seekers in the translation market remain strong in today's world. However, new translation graduates often get confused when it comes to how to get ahead in the profession. This paper aims to achieve the following:

- Investigating and tracking the first typical post-graduation steps towards becoming an established professional in the industry.

- Exploring job opportunities and barriers to the translation profession for students graduated from the translation department of Tripoli.

- Presenting suggestions that could serve future developments of the Translation Department of Tripoli.

- Based on the experience of others, the study aims at providing a helpful guide plan that could benefit students, seniors, and even graduates.

Overall, this study is primarily designed to understand the employability characteristics of bachelor's degree graduates from the translation department at the University of Tripoli. The research uses various information sources to explore the labor market 
experiences of those who obtained a translation degree between the years 2016 and 2020. Specifically, the study attempts to address the career pathways taken by recent translation graduates in Tripoli, field skills of new graduates required for the professional practice of translation, the time duration spent searching for a job, and the earnings and salary intakes of new graduates. It is assumed that collecting feedback from recent graduates will provide important information that will benefit new graduates, students, and will serve the development of the Translation Department of Tripoli.

Moreover, the study aims to examine the perceptions of recent graduates concerning the overall quality of translation education and training and determine whether skills acquired at university contributed to successful employment and development of their careers. Furthermore, it focuses on identifying the skills and knowledge relevant to professional practice, coupled with the identification of knowledge and skills that graduates are lacking. The study also intends to identify the knowledge gap between academic training and that needed by professional practice. In turn, understanding this gap would allow the development of effective learning and training of students.

\section{Literature Review}

Market research plays a significant role in modern business practice. Thus, market research must be conducted among market participants in order to produce products and services that can respond to market demands. It is crucial to broaden the role of tertiary education curriculum beyond passing on theoretical and practical knowledge to successfully prepare students for the $21^{\text {st }}$ century job market. Graduates need to be able to effectively engage in and adapt to the increasingly changing market. Therefore, the education curriculum should take into account the employment market, the individual needs of students, and the social needs in order to develop a skilled workforce that can respond to the needs of the professional field.

To better understand available data, this section is categorized into units addressing major themes in the current literature. Current studies on the translation market have frequently chosen to focus on evaluating translator training and education, employability, and the importance of technology knowledge in the field. Meanwhile, this study has chosen to focus on the current status of new graduates in the translation market in Tripoli. This section will discuss previous studies on some major themes that impact the transitioning process of graduates from higher education into the labor market.

\subsection{Employability of translation}

Employability presents an emerging issue nowadays, partially due to the increasingly competitive job market. Pool \& Sewell (2007) define employability as possessing a set of skills, knowledge, understanding, and personal attributes that increase individuals' chances of obtaining successful jobs which benefit them, the community, the workforce, and the economy. According to Harvey (2003), employability is much more than just getting a job after the completion of studies. Students need to develop the techniques and abilities that will enable them to progress in the current market. Harvey draws attention to the importance of developing critical, reflective abilities, empowering and enhancing the learner. Employers have definite expectations of graduates and assume them to have broad knowledge, skills, and qualifications such as the use of technology, communication, CAT tools, and specializations of areas. However, students seem to lack skills, qualifications, and proper guidance when applying for jobs. According to Yorke (2004), employers expect education to give students the knowledge and skills they need to be actual contributors to their desired field of work. However, employers notice that graduates lack several skills required for their business. Employers are concerned that graduates cannot transition smoothly from graduation to employment (Stephens \& Hamblin, 2006). A survey of representatives of the Canadian Translation Industry Sectoral Committee revealed a significant gap between the demands of the translation services market and the level of professional translator skills obtained by students throughout the course of their studies. The survey has also shown that employers find that the universities fall short of meeting their expectations regarding the training of new translation graduates in terms of required skills and preparation for being in the workforce. When hiring new graduates, the major obstacles encountered include their limited exposure to culture, lack of practical training, and the inability to work independently. Translation firms consider university training to be too theoretical. (Canadian Translation Industry Sectoral Commission, p. 19).

\subsection{Translation education and training}

In recent years, the translation industry has transitioned from an unknown professional activity to an increasingly growing economic activity that plays a significant role in generating sales, revenues, and employment around the globe. In Malaysia, the New Economic Model (NEM) was developed to improve the nation's income from middle to advance by 2020. Malaysia aimed to develop a competitive economy whose citizens enjoy a high-quality life, having attained a high-income level. To achieve this, Malaysia should revert to sustained and systematic programs to equip students with the Advanced English proficiency required to compete globally. However, data from the Ministry of Higher Education revealed that about a quarter of graduates from local universities remained unemployed six months after graduation in 2008. Employers have claimed that the main reason for the decline is the graduates' levels of English language. Most academics have no dispute about the relation between English Proficiency and Career Success. 
Ball and Chik (2001) find a significant relationship between income levels and gender, self-esteem, ownership, duration of employment, and English proficiency. Newman et al. (1997) mention the importance of cognitive, affective, instructional, curricular, and school-based factors vital for English speaking and reading skills. However, they stressed that the pragmatic requirements must be taken into account when designing curriculum.

In current literature, the gap between the universities' educational systems and the professional translation market is significant. However, it is not the main role of higher education to grant jobs for graduates; educational institutions must prepare students to enter the $21^{\text {st }}$ century job market. Academics and faculty mentors are stakeholders in graduates' success. They need to educate the students to become efficient and effective information seekers and users (Popescue and Popescue, 2003). Furthermore, translators must be trained right from class to withstand the translation market standards. Sofer (1999) states that translators must develop search and research techniques and obtain essential reference sources to produce a high-quality translation. If translators do not have a good command of such techniques, they may not be able to translate texts related to specialized subjects and fields. In the training literature, there are two approaches to teaching professional skills: (1) Preparing students for what the market expects from a professional, (2) Flourishing students with skills that allow them to adapt to the increasingly changing market demands. Pym (2009) states that the curriculum in translator training depends on the views held in the respective educational establishments. Mainly, does the training serve the needs of the market? Should teachers in higher education be professional translators themselves? He claimed that the invitation of professionals into the classroom is a significant step in the right direction. Pym's perspective suggests that changes in the market require continual and serious rethinking of the methodologies in the classroom. The description of universities' educational systems shows that they have been established to train component translators for the translation market and furnish them with various skills required for the graduate to be employed in the market.

Yet, university training programs focus mainly on linguistics aspects and translation theories. The training must be supplemented with other vital components and skills that are useful for professionals, for instance, documentation techniques, use of tools, computer resources and technology, and fields of specialization such as economics, medicine, and law. Gabr (2001) emphasizes the need to put knowledge into practice, rather than focusing only on theoretical contents, and the necessity to make students aware of how translation is practiced in 'the real world'. Classroom experience and academic advising do not always provide an accurate depiction of work-life, resulting in students' unstable transition from college to work. Appropriate training and preparation for employment is frequently a missing component. Faculties and students both agree that academic advising, a form of mentoring, needs improvement are need for better performance (University of Kentucky, 1996; Liu et al., 2009).

A University of Kentucky student satisfaction survey administered to graduates found that one of the top five factors identified by students and faculty for needing improvement was academic advising (University of Kentucky, 1996). Kiraly, a translation scholar, who wrote about the link between translator education and translation market, argues that providers and designers of programs need to take advantage of the market as a source of information, as he states:

If we want our products and services to be accepted by the market, we must conduct survey research among market participants. If we want to investigate the efficacy of the Translator Education Programs we offer, one of our main sources of information will be the translation services market. (Kiraly, 2005, p. 1099)

Employers have the ability to let the educational system know their needs; it could be useful for employers and higher education to benefit from one another and view each other as a valuable resource. At the same time, higher education institutions do not control the labor market and cannot guarantee employment outcomes (Holmes, 2013). The translation programs must design training strategies that can develop professional information skills.

\subsection{Translation and IT Skills}

The Internet and the proliferation of electronic information resources are of vital importance in the translation industry. The link between translators and computer tools is strong. Students must stay updated about new computer technology. Therefore, students must be familiarized with all electronic and computer tools available and used in professional work (Gouadec 2000). In the translator-training literature, there are various perspectives on how and to what extent technological skills should be taught in training programs. Mossop (2003, p. 21) argues that "students need basic skills to use Windows, Internet, E-mail, and Word and that they can learn the rest later."

Nevertheless, other translator profiles require students to graduate with advanced computer and technology skills, ranging from advanced word-processing skills to using translation memories and terminology management tools (Mackenzie 2004, Aula. int 2005, Optimale 2012). Furthermore, Pym (2013) states technology should be incorporated into the whole training process rather than being treated as a separate component of translation competence. As a result of this integration, technology is likely to affect all other aspects of a training program, as well as the learners' final professional profile. Translation technologies represent an interesting new area of interdisciplinary study that lies between computer science and translation. The development and 
growth of this new interdisciplinary field depend on its academic progress and the effective incorporation of translation technologies in the translators' education and training program. Mossop (2003, p. 21) notes that "if you cannot translate with pencil and paper, you cannot translate with the latest technology." he believes that translating with pencil, paper, and print dictionaries were means of the past. In contrast, today's translation practice is done using computers and technologies. Thus, if training programs aim to teach translation practice, teaching computer and technology skills must also be required.

\subsection{Effectiveness of CVs}

Concerning the translation job market, the current industry's institutions and companies try to evaluate candidates even before any interview, asking for their CVs. It is vitally important to create a CV that distinguishes the applicant from the rest of the candidates. A well-thought-out and strong persuasive CV is the most assured ticket in the job-seeking process and competing in today's labor market.

A CV is a short document and a record of the graduate's education and employment experience. It is an essential personal marketing piece for promoting to a potential employer. The CV determines the first impression an employer makes about an applicant. Therefore, it must create a flawless impression. When searching for a job, the applicant's CV is the most valuable tool to pass the interview stage. In the translation industry, certain aspects should be considered before applying for a job, which can be crucial to the development of graduates in the translation labor market.

According to How to Become a Certified Translator, an eBook written by Adriana Tassini, the top translator resume tips include; writing a short paragraph that explains why the applicant would fit the company, a summary of qualifications, years of experience, familiarity with computers, and additional curriculum courses the translator have taken. Moreover, Adriana explains that the translator's resume should include 1-3 bullet points about interpersonal skills and ability to work in a team, a list of previous workplaces, and all the languages the applicant is specialized in translating. At the bottom of the resume, education and professional training should be provided, such as names of attended schools and all of the translation certifications obtained. A resume should be easy to read, and applicants should make use of their skills, experience, graduations, qualifications, and language skills. The graduates should use a professional summary in marketing their translation skills because the success of any application largely depends on how well they present their skills in the resume.

Roboon (2021) states that "The development of soft skills is essential in equipping students for the future of work and preparing them for their graduate careers." she argues that a college degree is not required when applying for a job. However, it is certainly a must. Schooley (2019) reveals that "It depends on what type of business and industry you're entering; however, everyone should have some basic knowledge in business management, marketing, taxes, and sales". Grech (2019) told Business News Daily that if the applicant does not meet the education requirements, looking at what's listed as the minimum and preferred requirements can be beneficial. If a particular degree is preferred, it is still worth applying for the job, as long as the applicant meets the other major job requirements.

Bortz (2021) states that "even if you do not have a college diploma you can still showcase your achievements. Create an "honors and awards" section on the resume and list any professional certifications, training programs, or other educational credentials that you have under your belt". The application for an academic position obliges incorporating significant academic achievements such as a bachelor degree, master degree, awards, prizes, and scholarships. Further, it highlights any publications, conference papers, conference organizations, relevant strengths, and teaching experience. Meanwhile, applying for a post in the industry or business requires solid linguistic skills, IT skills, and attending extensive training courses.

\section{Methodology}

This section provides detailed information about the research methodology of the study. It outlines the research approach and strategy, data collection methods, selection of the sample, type of data analysis, and research limitations. The study uses a survey to collect data from a sample of translation graduates who graduated over the past six years. Since the investigation includes both descriptive and inferential statistics, a questionnaire was delivered to graduates. It asked questions concerning the following aspects of the current situation of the translation profession in Tripoli:

- Job opportunities

- Economic condition

- Social condition

- Translation education

- Market requirements and qualifications

The study entirely relies upon data gathered via the questionnaire which was administered to graduates from the Department of Translation at the University of Tripoli. Hence, an online questionnaire is produced in the hope of contacting as many recent 
translation graduates as possible to investigate the reality of employment for new translation graduates in Tripoli. The instrument for this study intends to elicit answers with which all the research questions can be answered.

\subsection{The participants}

The study sample comprises graduates holding a Translation bachelor's degree from the University of Tripoli between 2016 and 2020. The Department of Translation provided the researchers with a list of students' names who graduated from the translation department over the past five years. The number of participants is dependent on the point of data saturation; this means sampling continued until no new data emerges. After receiving approval to conduct the study from the DoT, a structured questionnaire was produced to collect the required data from the participants. The questionnaire is designed to obtain the required information with emphasis on the objectives and questions of the study. The participants were informed about the various purposes of the research which include, gaining an understanding of the graduates' experiences in entering the translation job market, the available opportunities, and how academic training prepared them to transition from university to the labor market. Participants received a link to the questionnaire along with a message that explains that the survey is very brief and will only take about 3 minutes to complete and includes inquiries about their experiences in the job market. Criteria for eligibility to participate in the study include a) Graduate of University of Tripoli's Translation Department. b) Degree attained within the past five years.

\subsection{The data collecting instrument}

The data-collecting instrument of the study is an online questionnaire that comprises a total of 15 questions compiled using a default online template. The online template offers various questions and response options. Besides the classic multiple-choice, it also provides the possibility of using a matrix, which allows the respondents to select more than one choice per question. Some questions in the survey also include the option (other) for respondents to add their own option. The language of the survey is English, and it comprises 14 multiple-choice questions, one rating-scale question, and one text box for further comments. The survey includes general questions about the status of the translation profession in Tripoli. The first questions focus on practical information, such as whether the graduates worked as a translator and if not what are the reasons, the time spent searching for a job to land that first position after graduation, types of jobs obtained since graduation, average salary, and respondents' current jobs. Part of the survey is dedicated to discussing the qualifications, skills, and years of experience often desired by employers. Some questions focus on evaluating the academic training and the importance of knowledge of translation technology in increasing employment chances of graduates, In addition to including questions about opportunities obtained abroad and the impact of the current situation in Tripoli on their job-seeking experience.

\subsection{Data-collecting procedure}

The distribution of the questionnaire capitalizes on the "small world phenomenon" of connectedness and collaborative spaces (Herrero 2006: 111). Therefore, the link to the questionnaire is distributed through personal contact, from individual to individual, by mailing a list of recent graduates provided by the Department of Translation at the University of Tripoli. A total of 100 graduates completed the survey. The few instances of invalid answers were filtered out and did not form part of the analysis. According to Oppenheim (2000: 149), attitudinal validity remains one of the most problematic aspects of social research and one with no clear solution in sight. Hence, the figures should be viewed as providing a general indication of the status of the translation profession for new graduates in Tripoli. Despite the limitations of the database, it can still provide some interesting insights into the current state of the translation profession in Tripoli, as well as providing information about the types of jobs available for new graduates, employment conditions, required skills, and qualifications that are in demand by employers. Each individual has unique personal experiences that could present some interesting insights into the current state of the translation profession in Tripoli.

\subsection{Procedures of data analysis}

The questionnaire for this research was compiled using the online free survey administration software (Google Forms), which besides offering users the ability to create and edit surveys online for free, it also provides a statistical analysis of the data from the completed questionnaires and automatically creates a summary of responses that builds visual representations of closeended questions (e.g., multiple-choice, checkbox) by isolating variables and segments that are important to the user. Moreover, the collected information can be automatically entered and saved into a spreadsheet which offers additional analysis features and allows users to access and edit responses. In this paper, the data analysis procedure entirely depended on the statistical analysis and the summary of responses provided by the online software. Some answers were analyzed separately using Google spreadsheets and Excel spreadsheets. In addition, two main branches of statistical methods were used: Descriptive statistics and Inferential statistics. Descriptive statistics helps describe, show or summarize data in a meaningful way, thus allowing simpler interpretation of the data. Inferential statistics are techniques that allow the use of samples to make generalizations about the populations from which the samples were drawn. In most researches conducted on groups of people, both descriptive and 
inferential statistics are used to analyze results and draw conclusions. Multiple answers and invalid replies found in the data were omitted and not included in the analysis.

\section{Results and Discussion}

This section is devoted to analyzing and interpreting the findings of the survey. The results of the analysis provide some interesting insights into the current situation of the translation profession in Tripoli. The following section of the paper will provide a discussion of data from the database under the following headings: job market and employment conditions of translation, types of jobs, skills and qualifications, experience, domains, salary and income, evaluating university academic and technical training, opportunities abroad, the effect of social conditions on employment.

\subsection{Job market and employment conditions of translation}

Typically, after obtaining a degree in translation, most graduates immediately start their journey in finding and exploring career options offered by the market. However, a significant factor that affects employability is the continuously changing job market. Figure 1 illustrates whether or not there are enough job opportunities available for new translation graduates in Tripoli. Based on evidence from the database, over half of the participants (72\%) agree that the translation market does not offer enough career opportunities for new graduates. Meanwhile, about (28\%) of the participants believe that the job market does indeed provide jobs for jobs for those working hard to pursue a satisfactory position. These findings reflect the shortage of job opportunities in the translation job market in Tripoli, which

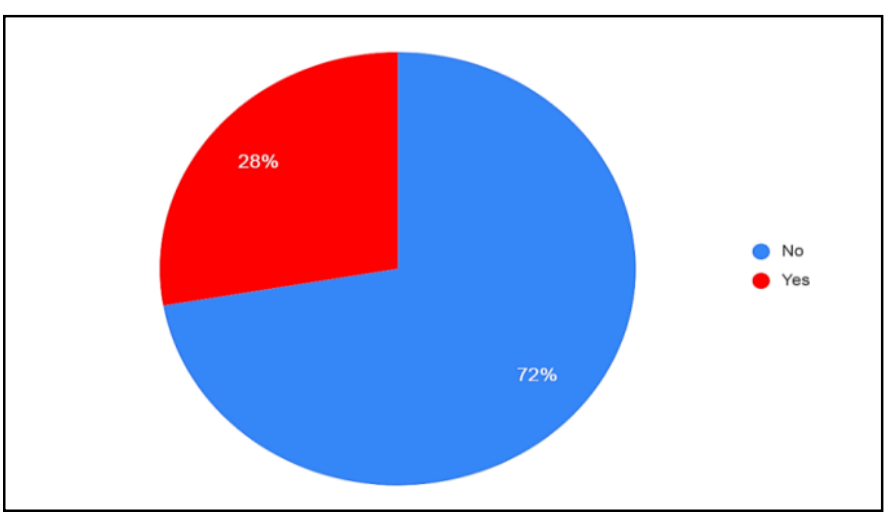

Figure 1: Are there enough job opportunities available for new translation graduates in Tripoli? (100 responses) seem to be quite reasonable as the results of another question the survey reveal that only (48\%) of the participants have worked as translators since graduation. It also explains why most participants tend to work in different areas rather than translation, further examination will be provided in the upcoming sections.

Although the data in the preceding section indicates low job opportunity rates in the translation market in Tripoli, the results from a question investigating the amount of time spent searching for a job reveal that (28\%) of the participants managed to secure a job within only the first few weeks after graduations. Furthermore, almost a third (34\%) of the proportion spent about a few months searching for a career. The data from the above chart also indicates that about (20\%) of graduates took 1-2 years to finally get hold of a suitable position. Despite the fact that most graduates agree that the current translation job market in Tripoli does not offer enough opportunities, it is evident that the vast majority of recent graduates spent a significantly short amount of time to land

their first occupation after graduation. Thus, it can be predicted from these results that a large proportion of

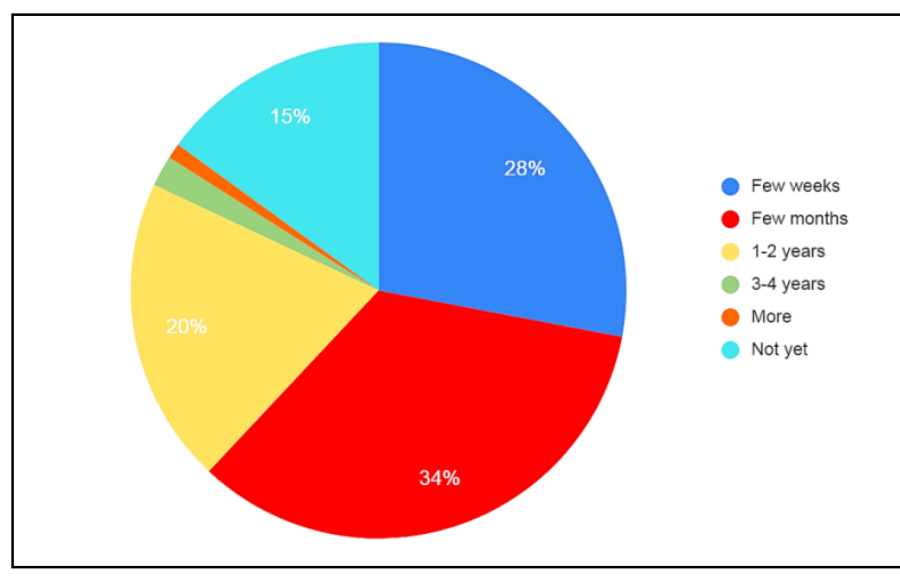

Figure 2: Time period spent searching for a job (100 responses) participants do not work in the translation sector.

When graduates are asked whether they have worked as translators at least for some time, the findings in the database demonstrate that slightly under half of the respondents (48\%) have worked as translators before. On the other hand, the remaining (52\%) confirm that they have not chosen to work in the translation profession after getting their degree. Furthermore, the participants are also asked to state the reasons which halt their way from working in the translation industry. Examine Figure 3 below. 


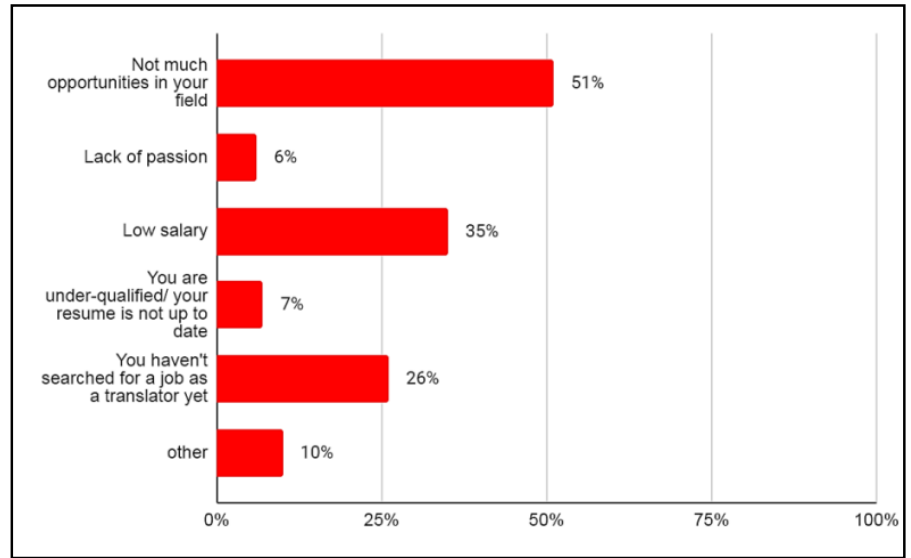

Figure 3: Reasons preventing graduates from working in the translation sector (optional)

The findings show that the main reason preventing graduates from working as translators is the limited job opportunities in the translation market. Half of the respondents (51\%) claim that they are yet to work as translators and state that the translation market largely lacks job opportunities. The results also reveal that (35\%) of the respondents have salary dissatisfaction and believe that translators are underpaid and work for lower fees. However, (26\%) of the respondents have not searched for jobs as translators yet. Meanwhile, (6\%) report that it is due to their lack of passion for the profession. The findings also note that (7\%) of the participants say that they are under-qualified in terms of skills, knowledge, their CVs are not up to date. Further reasons suggested by participants include some employers requiring MA degree, and employers' lack of trust in new graduates.

\subsection{Types of jobs available for translation graduates}

The survey yields the following results regarding the types of jobs the graduates have obtained since graduation. Given that the respondents are allowed to choose more than one option, Figure 4 below shows that language teaching is the most popular career option amongst graduates. Significantly, more than half of the graduates surveyed (64\%) have previously worked as language teachers. Moreover, the data shows that (37\%) of respondents have chosen translation as an occupation after finishing their course of studies. In contrast, the database records low rates for both government-related and interpreting professions, which fall around (12\%) and (6\%) respectively. In terms of professions not included in the survey but entered by participants, the entered data reveals that some participants have worked in banks, companies and administrations, customer services, and Human Resources.

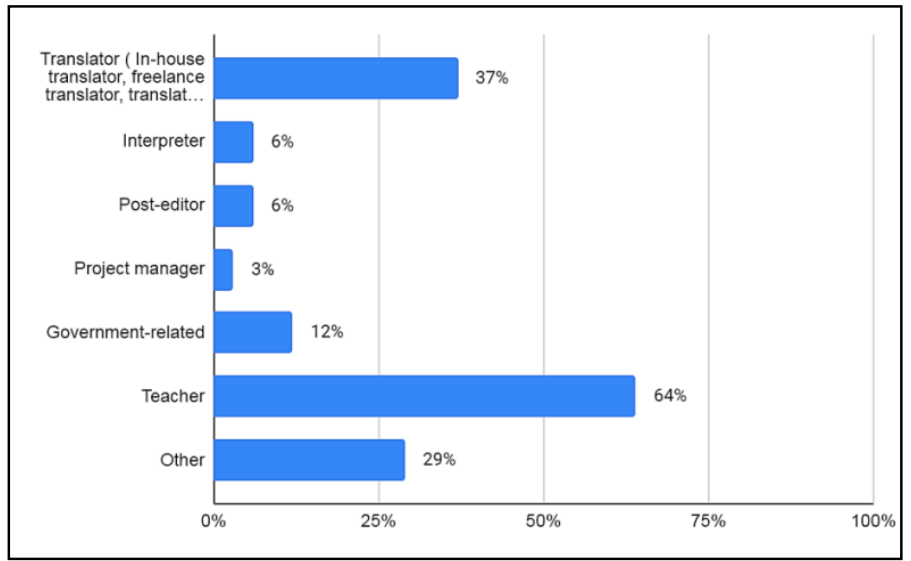

Figure 4: Jobs obtained by graduates since graduation (100 responses)

One of the most prominent features of the database is that language teaching is the first substantial alternative to translation amongst most graduates, making it clear that it domains other professional activities. Since language teaching scores the highest rates, it is safe to say that education is a way of quickly entering the market after getting a degree.

\subsection{Skills and qualifications}

In addition to carrying a bachelors' degree, employers typically expect candidates to acquire a variety of skills to assure that their future employees will be capable of handling the tasks demanded to them. The bar below shows the findings of additional qualifications translation graduates could acquire to add up to their CV. The participants were allowed to select more than one option. The results illustrated in the database show that obtaining specific international certifications in computing knowledge 
such as the International Computer Driving License (ICDL), in addition to advanced language knowledge such as (IELTS, TOFEL) might be crucial for most candidates in terms of enhancing their resumes and boosting employability.

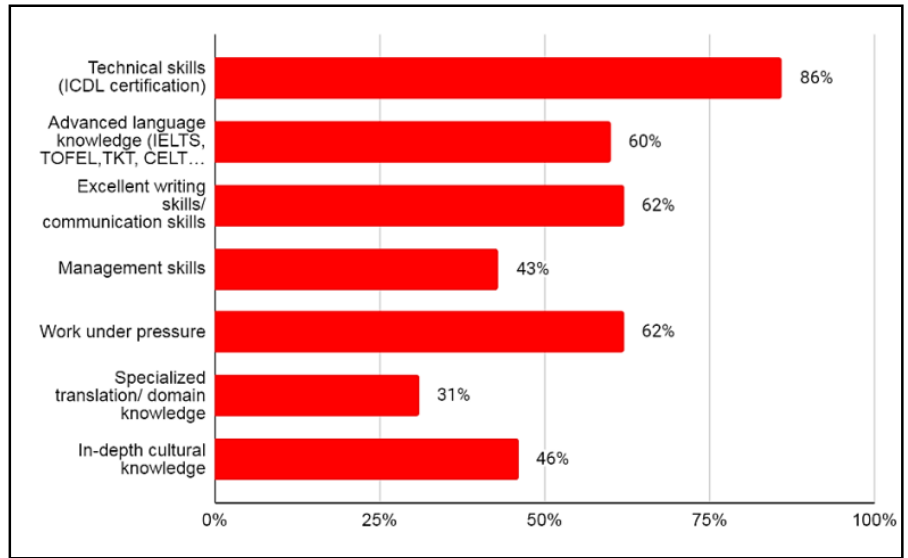

Figure 5: skills and qualifications that add up to a graduates' CV (100 responses)

According to Figure 5, (86\%) of the participants specify computer literacy (e.g., ICDL certification, good command of commonly used office programs, knowledge of basic computer skills, and the Internet) as the most sought-after skill by employers in the current job market. These findings are in line with the results of another question in the survey which revealed that about (80\%) of the participants agree that knowledge of translation technology is highly valued in the job market. In contrast, the remaining (20\%) seem to disagree with this perception. Over half of the participants (62\%) indicate that candidates who display excellent writing skills and communication skills will often stand out in an application pool. The results also show that (60\%) of respondents believe that a person equipped with a set of English language proficiency or advanced language knowledge (e.g., IELTS, TOFEL, TKT, CELTA.) can smoothly excel in the business world and has higher chances of securing better job opportunities. However, the database does reveal that (64\%) of graduates state that candidates should be able to work under pressure. In comparison, (43\%) suggest that employers appreciate attaining management skills (e.g., planning, organizing, coordinating, directing, leadership.) as such skills are considered vital for any organization to succeed and achieve its goals and objectives. Indepth cultural knowledge records a response rate of (46\%), while area specialization accounts for (31\%) of responses.

\subsection{Experience}

A period of work experience is an excellent addition to an applicant's CV. It can help demonstrate a candidate's capabilities and commitment to an employer. According to the database, nearly half of the participants (43\%) agree that most employers prefer to hire candidates with 3-4 years of experience. However, about (31\%) of the respondents claim that employers do not specify precisely how much experience is required.

As outlined in Figure 6, the third most common requested amount of experience is $1-2$ years (15\%), followed by 5-6 years (9\%). The lowest amount of experience requested is 7-8 years or more. The data in the database reveals that some employers are willing to hire new university graduates, which indicates that the industry is indeed making efforts to increase work placement opportunities for inexperienced professionals and help them enter the labor market. The findings can also explain why it took most graduates only a few months to obtain their first position in the market, as it has been indicated in Figure 2.

\subsection{Domains}

Regarding the domains in which translators are of significant demand in Tripoli, the data identify Business and Education as the highest in demand of translators with business scoring (51\%) of respondents' voices, followed by education with (48\%) rate of

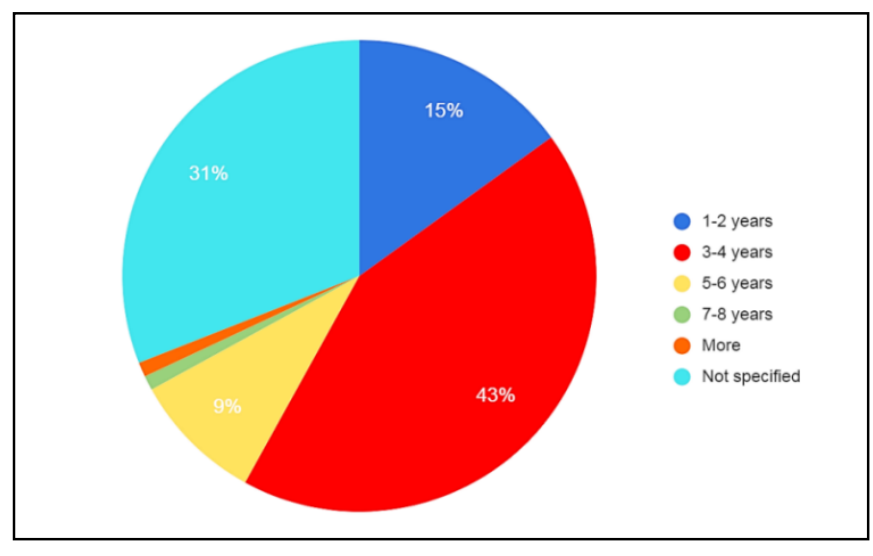

Figure 6: Years of experience desired by employer (100 responses) responses. Moreover, due to the current unstable situation in Tripoli, it is not surprising to see that (37\%) of participants believe that fields related to law are often willing to hire translators. The need for translators in Government related fields accounts for (32\%) of responses and (28\%) for fields related to various areas of information technology. Art and culture record almost similar results to finance, with (24\%) votes for arts and culture and (23\%) for finance. Similarly, literary and audiovisual fields show close results recording response rates of (18\%) and (17\%) respectively. 


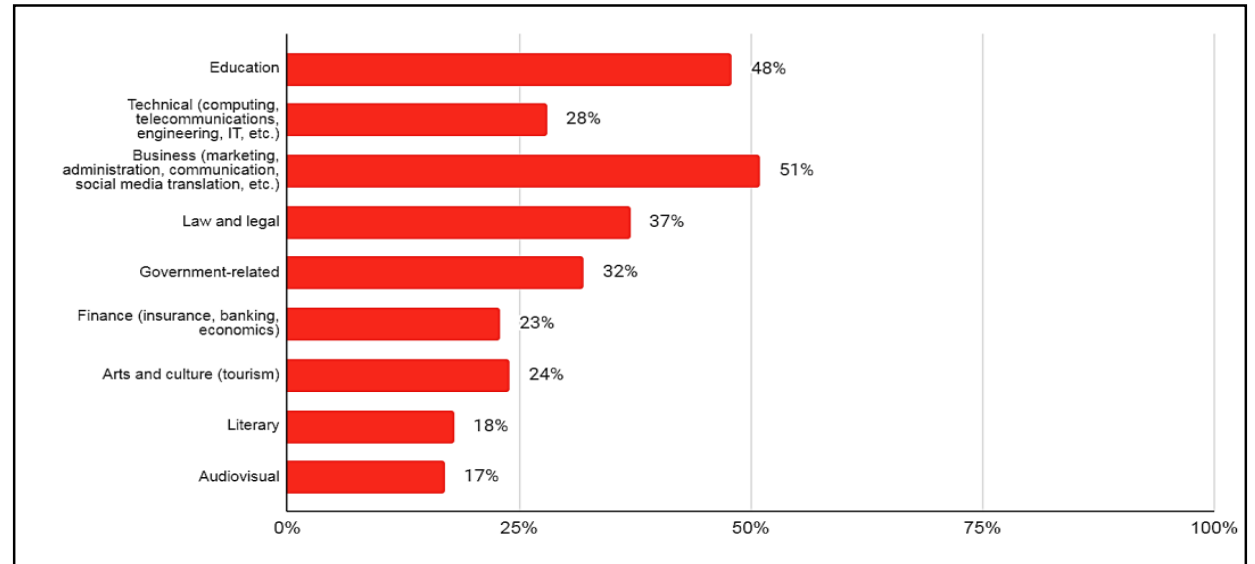

Figure 7: domains that often search for translators to hire (100 responses)

As the findings indicate, translators are greatly sought after in fields related to various business areas in Tripoli; this may be explained due to the fact that the country is experiencing a growing interest from foreigners to establish a business presence and start investment programs in Tripoli. Furthermore, the increasing number of international schools with English curriculums in Tripoli has led to a great demand for language experts, offering translators the option of working in the education industry. Moreover, the significant demand for translators in fields related to law and legal raises the argument concerning why the Department of Translation in Tripoli should consider adding legal translation into the curriculum.

In relation to the previous findings, when recent graduates are asked about their current job, the results revealed that the majority of participants (43\%) appear to be working as teachers, and about (31\%) are currently working in companies and organizations. These outcomes seem to strongly support the previous findings of education and business being the most dominant fields in which translators are required. However, only (17\%) of respondents work as translators and a very small proportion of the population (9\%) work in government-related fields. The remaining responses included jobs such as working in banks and hospitals.

\subsection{Salary and income}

In the translation literature, it is often claimed that salary or income are considered to be important status parameters (e.g., Chan 2005). However, despite salary being a great indicator of status, it should not necessarily be considered a decisive factor (Dam and Zethsen, 2011). In this research, the participants are asked to indicate their average salary as translation graduates even if they do not currently work in the translation industry by marking one of the following monthly income ranges: 300-500 LYD, 600-800 LYD, 900-1100 LYD, 1200-1400 LYD, 1500-1700 LYD, 1800-2000 LYD, more than 2000 LYD. In this part, the analysis will adopt a method used in a similar study conducted by Dam and Zethsen (2011) titled (The Status of Professional Business Translators on the Danish Market: A Comparative Study of Company, Agency and Freelance Translators), in which the two scholars summarize the results by merging ranges into three major categories: below-average, average, and above-average. In this context, the category referred to as below-average covers salary ranges given in the questionnaires as 300-800 LYD, whereas the average category covers the income ranges 900-1400 LYD, and above-average covers the highest salary ranges in the survey 1500-2000 LYD or more.

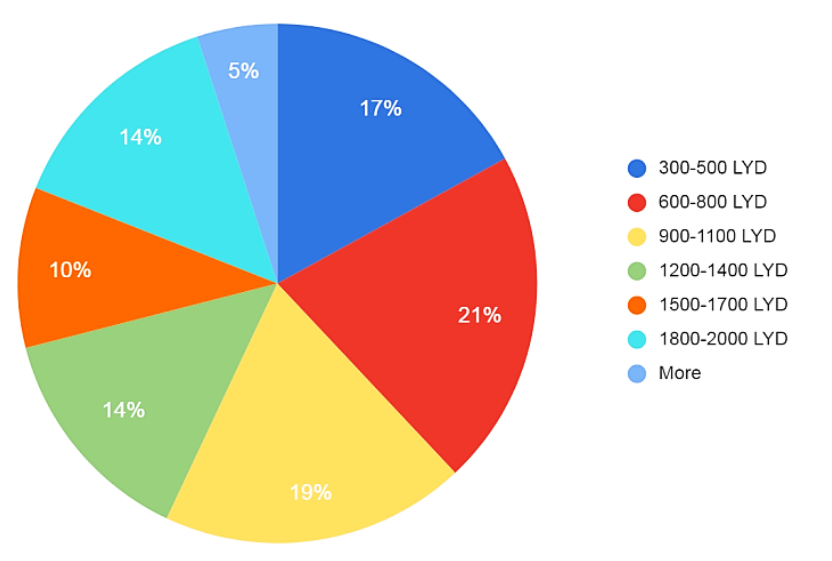

Figure 8: Average salary a translation graduate receives per month (100 responses) 
As illustrated in the chart above, most participants record income levels below-average with (21\%) of responses claiming that their average salary as translation graduates ranges between 600 to 800 LYD, and about (17\%) of responses account for the salary range 300-500 LYD. However, despite the majority recording below-average income levels, a considerable proportion (19\%) state that they receive average salaries, which range between 900 to 1100 LYD, and (14\%) of the participants say that they get paid between 1200 and 1400 LYD Per month. As for graduates with above-average earnings, (14\%) of them confirm that they receive a monthly income that ranges from 1800 to 2000 LYD, whereas (10\%) of responses get paid an average of $1500-1700$ LYD Per month. Only a small percentage of participants (5\%) receive above 2000 LYD per month, which indicates how rare it is to claim more than 2000 LYD a month as a translation graduate. These results are interesting and seem to be highly diverse depending on the person's occupational status. However, when analyzing individual responses and calculating the average salary of participants who are currently working in companies or those with government-related jobs, teachers, and translators, the results revealed that participants working in companies earn the highest salaries with an average of 1252 LYD per month. On the other hand, the average salary for the remaining common occupations is 1040 LYD for teachers, 1133 LYD for translators, and 1033 LYD participants with government-related jobs.

\subsection{Evaluating university academic and technical training}

Two questions are included in the survey with the aim of providing some valuable insights into the efficiency of the academic training of the Department of Translation in Tripoli. First, the participants are asked whether they agree that translation students of Tripoli University require more training before graduation. The results reveal that the mass majority (94\%) seem to agree, proving that the four-year translation training program was not efficient enough to produce highly qualified Translators. Similar results can be found in previous studies in which an assessment of university training is made. Bowker et al. (2004) claim that university training, in general, does not serve the needs of the labor market (Bowker, 2004; Chesterman and Wagner, 2004; Gouadec, 2007). The data shows a clear need for coordinating efforts to address university training and include components that prepare students for the marketplace.

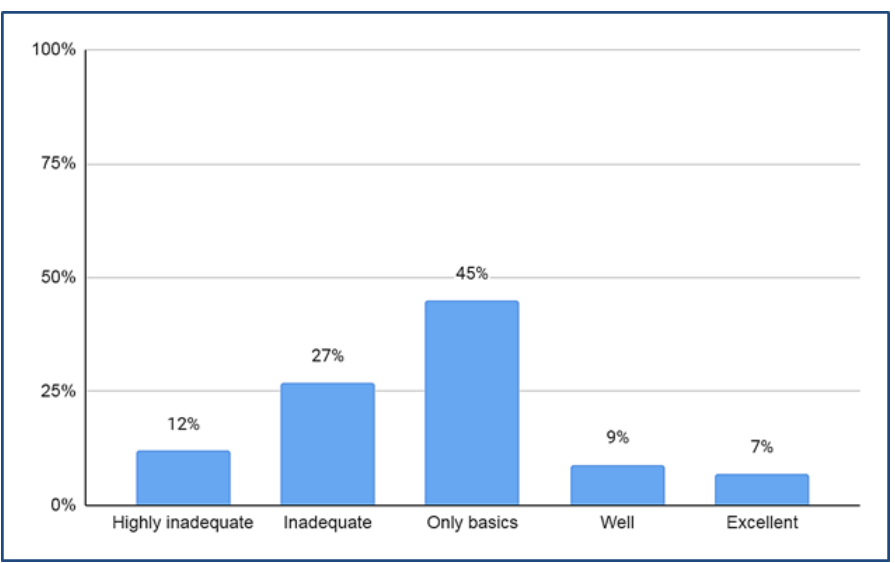

Figure 9: Evaluating the academic preparation for professional work (100 responses)

In the second question, the participants are asked to rate how well the academic training prepared them for professional work. The findings in Figure 9 show that only (7\%) of the respondents say that the academic training was excellent, whereas (9\%) claim that it was just well. Slightly less than half (45\%) agree that it only provided basic training. Nevertheless, $(27 \%)$ of the respondents say that the preparation was inadequate, and (12\%) state that it was highly inadequate and requires more improvements.

As illustrated in Figure 9, it appears the percentage of those who believe that their academic background prepared them well for the job market is deemed to be relatively low. The results suggest that graduates do believe that academic training is crucial to be identified as a qualified translator. However, according to most responses, the training program does not equip students with enough knowledge regarding translation technology, skills, and qualifications required by the market. Thus, it is concluded that the training program needs more professional competence.

\subsection{Opportunities abroad}

The survey also includes a question investigating the proportion of graduates who managed to obtain opportunities abroad with their translation degrees. Surprisingly, almost third of the population (31\%) claim that they were capable of landing an opportunity abroad using

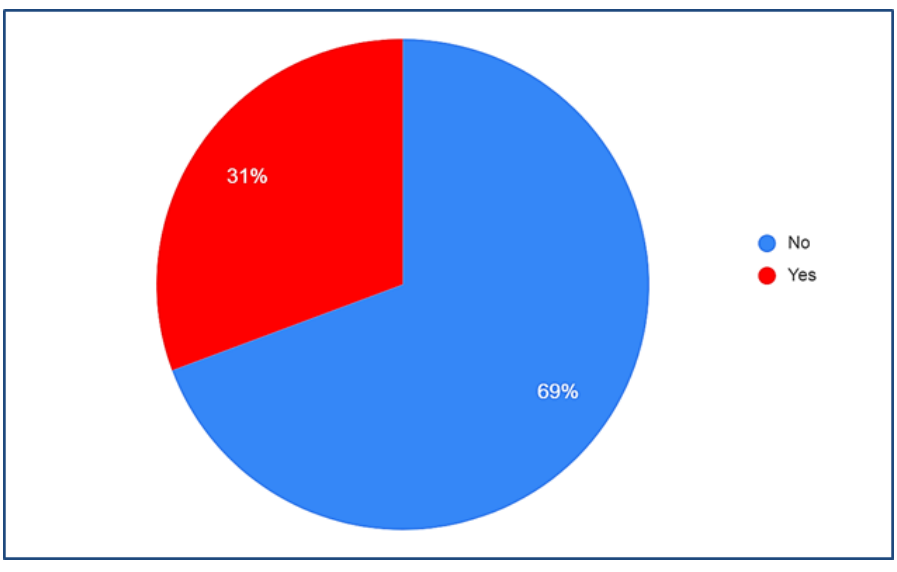

Figure 10: Opportunities obtained abroad with a translation degree (100 responses) their translation degree, which is a great indicator that certain countries are willing to approve on translation graduates aiming to establish a career abroad or even planning on finishing their studies in a different country. 


\subsection{The impact of social conditions on employment}

Figure 11 shows the impact of the current circumstances in Tripoli on the status of employment. A large proportion (\% 77) agreed that the country's unstable situation reduced their chances of obtaining a suitable job. In contrast, (23\%) seem to disagree. The significantly two different percentages indicate that the current circumstances can impose a great challenge for new translation graduate willing to start a career. Furthermore, the participants made some comments regarding this issue:

$>$ "Most of the answers could be changed if the situation in Libya was better."

$>\quad$ "It is difficult for me to pursue my goals due to the country's circumstances."

$>\quad$ "If there are more foreign companies, there will be more opportunities."

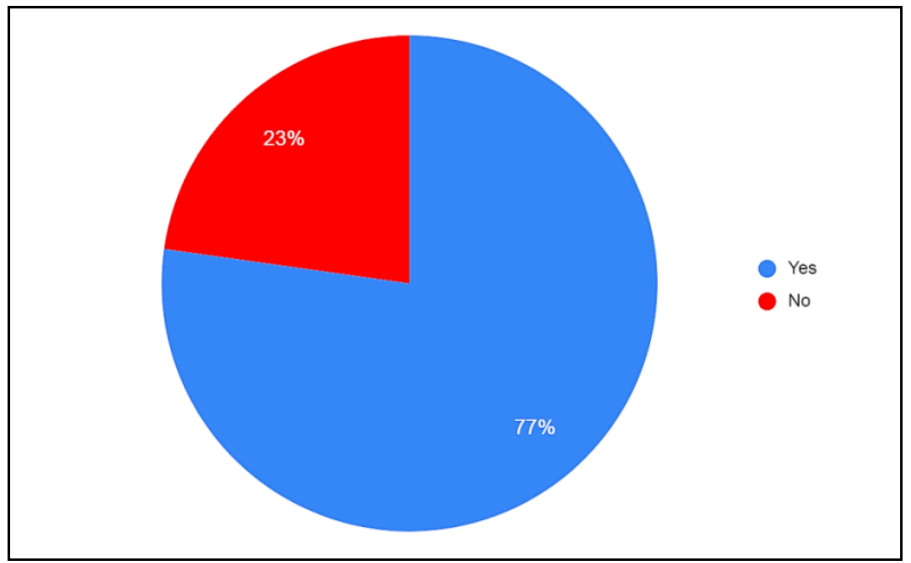

Figure 11: The impact of the current situation in Tripoli in reducing employment opportunities (100 responses)

Further comments are collected from participants, which included recommendations such as applying for multiple jobs and advising students to focus on tailoring their CV to the job they are aiming to get. Some participants emphasized the power of an updated, well-structured, clean and precise resume and its role in increasing an applicant's chances of getting interviewed. Other comments highlighted the importance of constantly practicing translation skills for students willing to work in the translation sector.

\section{Conclusion}

The present paper has examined the current state of the translation profession for new graduates in Tripoli. Particularly as viewed from graduates' perspectives, the results reveal some interesting insights into the status of the translation job market in Tripoli, such as the types of jobs available for translation graduates, employment conditions, and salary and income, and domains that often hire translators. The study also investigated the efficiency of the academic training of the Translation Department, as well as examining the impact of social conditions on the graduates' job-seeking experience. This final section will outline some of the main characteristics of the translation profession for new graduates in Tripoli, as portrayed through the database.

According to recent graduates, the current translation job market does not provide enough opportunities for new translation graduates, which was proven to be the primary reason that halted half of the population (51\%) from working in the translation industry. These results seem to be quite reasonable since the database shows that slightly under half (48\%) of the participants have previously worked as translators, whereas only (17\%) of the respondents currently work as translators. Nevertheless, the findings confirm that career options for individuals carrying a translation degree are numerous. For example, up to (64\%) of graduates have worked as teachers since graduation, and about (43\%) of them still teach up to this moment. Moreover, the database indicates that opportunities for translators in various domains are also considered to be diverse. Domains in which translators are highly required include Education, Business and Finance, Law, and Technical fields. These results explain how most graduates managed to secure a job within the first months after graduation despite of the limited job opportunities available in their field. Furthermore, the findings of the investigation done on the average salary of translation graduates in Tripoli demonstrate that the monthly income for most graduates ranges between 300-800 LYD. However, the database revealed a considerable proportion of graduates who receive an average of 900-1400 LYD monthly. On the other hand, individuals who get paid an average of 2000 LYD per month represented a very small percentage in the database. The findings also show that individuals working in companies have the highest income levels. 
Employers willing to hire translators seem to be quite aware of the skill sets and qualifications required to work as a translator in the $21^{\text {st }}$ century. Over (82\%) of graduates surveyed believe that IT knowledge and computer skills are considered to be vital and desired by most employers. However, it is evident that employers also highly appreciate skills that are crucial to producing highquality documentation, such as advanced language knowledge, excellent writing skills, ability to work under pressure, communication skills, in-depth cultural knowledge, and specialized translation knowledge. Nevertheless, years of experience required to enter the profession are not specified. Employers seem to be accepting and hiring candidates with relatively little experience, which draws the assumption that current employers could be using the qualifications-set mentioned previously to evaluate candidates with no significant amount of experience. These results indicate that it is entirely possible that applicants with less experience could be chosen over candidates with experience, and that the job market is indeed making efforts to assist inexperienced candidates to enter the workforce.

Translation graduates generally have medium to negative perceptions of the academic training program and claim to not have gained sufficient knowledge and did not feel prepared enough to enter the labor market. These results suggest that further efforts need to be made to improve the training criteria and to focus more on adding components required by the market. Moreover, most graduates state that the current situation in Tripoli has largely reduced their chances in the marketplace. However, a considerable number of graduates were able to land opportunities abroad using a translation degree.

\section{Funding}

This research received no funding

\section{Conflicts of Interest}

The authors declare no conflict of interest.

\section{References}

Ball, R., \& Chik, R. (2001). Early employment outcomes of home and foreign educated graduates - the Malaysian Experience. Higher Education Publisher: Springer Netherlands, 42(2), 171-189. https://doi.org/10.1023/a:1017579415737

Bortz, D. (2021). How to get around education requirements in job ads. Monster Worldwide [Online]. Available at: https://www.monster.com/career-advice/article/overcome-job-ad-requirements

Bowker, L. (2005). What Does It Take to Work in the Translation Profession in Canada in the 21st Century?. Meta, 49(4), 960-972. https://doi.org/10.7202/009804ar

Canadian Translation Industry Sectoral Commission. (1999). Survey of the Canadian Translation Industry.

Dacre Pool, L., \& Sewell, P. (2007). The key to employability: developing a practical model of graduate employability. Education + Training , 49(4), 277-289. https://doi.org/10.1108/00400910710754435

Dam, H., \& Zethsen, K. (2010). Translator status: Helpers and Opponents in the Ongoing Battle of an Emerging Profession. Target. International Journal Of Translation Studies, 22(2), 194-211. https://doi.org/10.1075/target.22.2.02dam

Dam, H., \& Zethsen, K. (2012). The Status of Professional Business Translators on the Danish Market: A Comparative Study of Company, Agency and Freelance Translators. Meta, 56(4), 976-997. https://doi.org/10.7202/1011263ar

Defeng, L. (2007). Translation curriculum and pedagogy. Target. International Journal Of Translation Studies, 19(1), 105-133.

https://doi.org/10.1075/target.19.1.07li

Gabr, M. (2001). Program Evaluation, A Missing Critical Link in Translator Training, Translation Journal.

https://translationjournal.net/journal/15training.htm

Gouadec, D. (2000). Rounding up, personal correspondence through an e-mail message to Kiraly, Donald. January 25th 2007, retrieved from http://groups.yahoo.com/group/itit/messages?o=1\&yguid=287085046

Allen, J., \& van der Velden, R. Transitions From Higher Education to Work. Higher Education Dynamics, 55-78. https://doi.org/10.1007/978-14020-5926-1 4

Herrero, L. (2008). Viral Change: The Alternative to Slow, Painful and Unsuccessful Management of Change in Organizations. Meetingminds.

Holmes, L. (2013). Competing perspectives on graduate employability: possession, position or process?. Studies In Higher Education, 38(4), 538554. https://doi.org/10.1080/03075079.2011.587140

Kafi, M., Khoshsaligheh, M., \& Hashemi, M. (2017). Translation profession in Iran: current challenges and future prospects. The Translator, 24(1), 89-103. https://doi.org/10.1080/13556509.2017.1297693

Katan, D. (2017). Translation Theory and Professional Practice: A Global Survey of the Great Divide. HERMES - Journal Of Language And Communication In Business, (42), 111-153. https://doi.org/10.7146/hjlcb.v22i42.96849

Katan, D. (2009). Occupation or profession A survey of the translators' world. Translation And Interpreting Studies, 4(2), $187-209$. https://doi.org/10.1075/tis.4.2.04kat

Kiraly, D. (2006). Project-Based Learning: A Case for Situated Translation. Meta, 50(4), 1098-1111. https://doi.org/10.7202/012063ar

Lukins, S. (2021). Why Are Soft Skills So Important In the Graduate Job Market?. Top Universities, https://www.topuniversities.com/studentinfo/careers-advice/why-are-soft-skills-so-important-graduate-job-market.

Lung Jan Chan, A. (2005). Why are most translators underpaid? A descriptive explanation using asymmetric information and a suggested solution from signaling theory. Translation Journal. http://www.translationjournal.net/journal/32asymmetric.htm. 
Mackenzie, R. (2004). The competencies required by the translator's roles as professional. Translation In Undergraduate Degree Programmes, 3138. https://doi.org/10.1075/btl.59.04mac

Mossop, B. (2003). What should be taught at translation school?', in Anthony Pym et al. (eds.) Innovation and e-learning intranslator training. Tarragona: Intercultural Studies Group. 20-22.

Myoung, S., \& Shunmugam, K. (2014). The Translation Profession in Malaysia: The Translator's Status and SelfPerception. GEMA Online Journal of Language Studies. https://ejournal.ukm.my/gema/article/view/5829/0.

NEAC: Malaysia losing skilled talent. The Star. (2010). https://www.thestar.com.my/news/nation/2010/03/30/neac-malaysia-losing-skilled-talent. Oppenheim, A. N. (1992). Questionnaire Design, Interviewing and Attitude Measurement. [Ebook].

https://dimas0709.files.wordpress.com/2018/02/a-n-oppenheim-questionnaire-design-interviewing-and-attitude-measurement-1992.pdf.

Popescu, A., \& Popescu, R. (2003). Building Research Skills: Course-Integrated Training Methods. Journal Of Professional Issues In Engineering Education And Practice, 129(1), 40-43. https://doi.org/10.1061/(asce)1052-3928(2003)129:1(40)

Pym, A. (2009). Translator training. ResearchGate, https://www.researchgate.net/publication/242711915 Translator training

Pym, A. (2014). Translation Skill-Sets in a Machine-Translation Age. Meta, 58(3), 487-503. https://doi.org/10.7202/1025047ar

Pym, A., GRIN, F., SFREDDO, C., \& CHAN, A. L. J. (2013). The status of the translation profession in the European Union. Anthem Press. https://doi.org/10.2782/64819

Schooley, S. (2019). Should You Skip College to Start a Business?. Businessnewsdaily, https://www.businessnewsdaily.com/6892-skip-college-forentrepreneurship.html.

Sofer, M. (2006). The Translator's Handbook.

Stephens, D., \& Hamblin, Y. (2006). Employability skills: are UK LIM departments meeting employment needs?. New Library World, 107(5/6), 218227. https://doi.org/10.1108/03074800610665211

Stone, C., Van Horn, C., \& Zukin, C. (2012). Chasing the American Dream: Recent College Graduates and the Great Recession. Work Trends. 1-64. https://journalistsresource.org/wp-content/uploads/2012/06/Chasing American Dream Report.pdf.

Neuman, S., \& Dickinson, D. (1997). Handbook of Early Literacy Research, Volume 1 [Ebook].

https://books.google.com.ly/books?id=afiqtldRQGwC\&pg=PA218\&lpg=PA218\&dq=research+the+important+of+English+Susan+B. +Newman\# $\mathrm{v}=$ onepage $\& \mathrm{q}=$ research\%20the $\% 20$ important $\% 20$ of\%20 English\%20Susan\%20B.\%20 Newman \&f=false.

Tassini, A. (2011). How to Become A Certified Translator. Certified Translation Professional.

https://translatorcertification.com/?fbclid=IwAR37irhsiG8TOpqY55tdax5K 6bcY4Y5C4Id66PYVI6luWi62vtr1-Ort04

Tirosh, O. (2021). Key Translation Industry Trends for 2021 and Beyond. Tomedes. https://www.tomedes.com/translator-hub/translation-industrytrends-2021. University of Kentucky (1996). Executive summary: Student satisfaction survey.Yılmaz-Gümüş, V. (2018). Solidity and

Professionalization of Translation: Turkey as a Case in Point. HERMES - Journal of Language and Communication in Business, (58), 43-63. Retrieved from https://tidsskrift.dk/her/article/view/111661 YORKE, M. (2004). Employability in the Undergraduate Curriculum: some student perspectives. European Journal Of Education, 39(4), 409-427. https://doi.org/10.1111/j.1465-3435.2004.00194.x 